\title{
Successful Treatment of a Case of First Bite Syndrome without Any Cause
}

\author{
Seong Ho Chang1,2*, Byung Sun Jun'3, Jong Ouck Choi'3, Jung Jun Kim³, Young Jang3 \\ ${ }^{1}$ Department of Anesthesiology and Pain Medicine, College of Medicine, Korea University, Seoul, Korea \\ ${ }^{2}$ Gwanak Otolaryngology, Anesthesia and Pain Clinic, Seoul, Korea \\ ${ }^{3}$ Gwanak Otolaryngology, Head and Neck Surgery Clinic, Seoul, Korea \\ Email: *torchid@korea.ac.kr
}

Received 28 August 2015; accepted 30 October 2015; published 3 November 2015

Copyright (C) 2015 by authors and Scientific Research Publishing Inc.

This work is licensed under the Creative Commons Attribution International License (CC BY).

http://creativecommons.org/licenses/by/4.0/

cC) (i) Open Access

\begin{abstract}
Background: For the first bite syndrome (FBS), various causes were suggested such as parapharyngeal space surgery, resection of styloid process, carotid endarterectomy, parotid gland tumor, submandibular gland tumor, and upper cervical surgery. Actually, the real cause of FBS is still not clear. Also, suggested methods of treatment for the FBS are botulinum toxin injection, laser tympanic plexus ablation, pharmacologic approach, and no treatment. The results of those treatments were not satisfactory. Aim: The authors tried to find out the adequate method of treatment for the FBS and also tried to figure out pathologic cause of the FBS through observation of the patient response to the treatment. Case Presentation: A 38-year-old male was presented at head and neck surgery clinic with a sharp pain on the left parotid area especially at the first bite of eating food for two days. There was no cause. The patient was given trigger point injections on his left sternocleidomastoid, masseter, and temporal muscles with left mandibular nerve block five times 3 - 4 days apart. Also small amount of oral anticonvulsants were added for four weeks. Before finishing taking oral medication, the pain was gone completely. Conclusion: The authors experienced a case of FBS with no detectable cause, and treated successfully with the methods of trigger point injection, mandibular nerve block, and oral antiepileptic medication.
\end{abstract}

\section{Keywords}

First Bite Syndrome, Mandibular Nerve Block, Oral Medication, Trigger Point Injection

\section{Introduction}

First bite syndrome (FBS) refers to facial pain characterized by a severe cramping or spasm in the parotid region

*Corresponding author. 
with the first bite of each meal that diminishes over the next several bites. It is supposed to be a potential sequela of surgery involving the infratemporal fossa (ITF), parapharyngeal space (PPS), and/or deep lobe of the parotid gland. Up to date, the incidence, risk factors, treatment options, and outcomes of FBS are poorly understood [1]. The authors came upon a patient with FBS for 20 days without any cause, and manipulated the syndrome successfully with the methods of trigger point injections, mandibular nerve block, and combined small amount of anticonvulsants carbamazepine and neurontin.

\section{Case Report}

A 38-year-old male was presented at head and neck surgery clinic with a sharp pain on the left parotid area especially at the first bite of eating food for two days. Before the appearance of the symptom, there was no other related event to cause the pain. Under the impression of inflammation of parotid gland, conservative medications were given for 18 days without any improvement. The patient was referred to pain clinic. He was given a piece of chocolate and at the first bite a severe sharp electric shock like pain occurred on his left parotid area. Also there revealed several tender points on his left sternocleidomastoid muscle, masseter muscle, and temporal muscle. The numerical pain scale at the first bite was 10/10. The first day of treatment, he was given trigger point injections (TPI) [2] and left cervical plexus block with $10 \mathrm{ml}$ of $1 \%$ lidocaine. After the injections the pain scale of the first bite was 2/10. After three days, the patient was given TPI with mandibular branch block of his left trigeminal nerve with $5 \mathrm{ml}$ of 1\% lidocaine and the pain was gone completely for a few hours. On the third visit (seven days after the first visit) the pain scale was 5/10. Oral medication (carbamazepine 200 mg and neurontin 100 mg daily) was added to TPI and mandibular branch block of 3 - 4 days' interval. After three more TPI and mandibular branch blocks with 28 days' oral medication the pain scale stayed 1 - 2/10 and before finishing taking the rest of the oral medication the pain disappeared completely. It's been more than a year since the patient became free of pain.

\section{Discussion}

The actual cause of the FBS is not clear. Reported cases are deep lobe parotidectomy [3], upper cervical surgery [4], ipsilateral carotid endarterectomy [5] [6], carcinoma of the submandibular gland [7], carcinoma of the parotid gland [8], resection of the styloid process [9], and other parapharyngeal space occupying lesions or surgery [10]-[14]. There is a suggestion that inadvertent ablation of the sympathetic nerve supply to the parotid gland is a cause of the FBS [15]. Actually, as we can see in the above several reported cases, other than direct parotid gland surgery could also cause the FBS. But this case revealed no special cause. For the treatment of FBS botulinum toxin injection [16]-[18], laser tympanic plexus ablation [19], and pharmacologic approach [4] [20] were suggested with no satisfactory effect. Linkov et al. [1] reviewed 45 FBS cases, got the result of partial resolution of FBS symptoms in $69 \%$ and complete resolution in $12 \%$, and found that even no treatment consistently provided effective symptomatic relief. In this case trigger point injection [2] of the left masseter muscle, temporal muscle, and sternocleidomastoid muscle, with nerve block of the left mandibular branch of trigeminal nerve, and combined oral medication of small amount of antiepileptic drugs [21] were tried successfully. Considering the patient's response to the therapy, FBS might be another manifestation caused by myofascial pain syndrome with or without trigeminal neuralgia.

In conclusion, the authors experienced a case of FBS with no detectable cause, and treated successfully with the methods of trigger point injection, mandibular nerve block, and oral antiepileptic medication.

\section{References}

[1] Linkov, G., Morris, L.G., Shah, J.P. and Kraus, D.H. (2012) First Bite Syndrome: Incidence, Risk Factors, Treatment, and Outcomes. Laryngoscope, 122, 1773-1778. http://dx.doi.org/10.1002/lary.23372

[2] Yoon, S.Z., Lee, S.I., Choi, S.U., Shin, H.W., Lee, H.W., Lim, H.J. and Chang, S.H. (2009) A Case of Facial Myofascial Pain Syndrome Presenting as Trigeminal Neuralgia. Oral Surgery, Oral Medicine, Oral Pathology, Oral Radiology, and Endodontology, 107, e29-e31. http://dx.doi.org/10.1016/j.tripleo.2008.09.026

[3] Houle, A. and Mandel, L. (2014) First Bite Syndrome after Deep Lobe Parotidectomy: Case Report. Journal of Oral and Maxillofacial Surgery, 72, 1475-1479. http://dx.doi.org/10.1016/j.joms.2014.02.010

[4] Abdeldaoui, A., Oker, N., Duet, M., Cunin, G. and Tran Ba Huy, P. (2013) First Bite Syndrome: A Little Known Complication of Upper Cervical Surgery. European Annals of Otorhinolaryngology, Head and Neck Diseases, 130, 
123-129. http://dx.doi.org/10.1016/j.anorl.2012.08.001

[5] Wang, T.K., Bhamidipaty, V. and MacCormick, M. (2013) First Bite Syndrome Following Ipsilateral Carotid Endarterectomy. Vascular and Endovascular Surgery, 47, 148-150. http://dx.doi.org/10.1177/1538574412469285

[6] Wong, E.H., Farrier, J.N. and Cooper, D.G. (2011) First-Bite Syndrome Complicating Carotid Endarterectomy: A Case Report and Literature Review. Vascular and Endovascular Surgery, 45, 459-461. http://dx.doi.org/10.1177/1538574411407084

[7] Guss, J., Ashton-Sager, A.L. and Fong, B.P. (2013) First Bite Syndrome Caused by Adenoid Cystic Carcinoma of the Submandibular Gland. Laryngoscope, 123, 426-428. http://dx.doi.org/10.1002/lary.23725

[8] Diercks, G.R., Rosow, D.E., Prasad, M. and Kuhel, W.I. (2011) A Case of Preoperative "First-Bite Syndrome” Associated with Mucoepidermoid Carcinoma of the Parotid Gland. Laryngoscope, 121, 760-762. http://dx.doi.org/10.1002/lary.21282

[9] Cernea, C.R., Hojaij, F.C., De Carlucci Jr., D., Plopper, C., Vanderley, F., Guerreiro, C.A. and Viana, M.S. (2007) First-Bite Syndrome after Resection of the Styloid Process. Laryngoscope, 117, 181-182. http://dx.doi.org/10.1097/01.mlg.0000245059.40028.ed

[10] Deganello, A., Meccariello, G., Busoni, M., Franchi, A. and Gallo, O. (2011) First Bite Syndrome as Presenting Symptom of Parapharyngeal Adenoid Cystic Carcinoma. The Journal of Laryngology \& Otology, 125, 428-431. http://dx.doi.org/10.1017/S002221511000294X

[11] Lieberman, S.M. and Har-El, G. (2011) First Bite Syndrome as a Presenting Symptom of a Parapharyngeal Space Malignancy. Head and Neck, 33, 1539-1541. http://dx.doi.org/10.1002/hed.21412

[12] Mandel, L. and Syrop, S.B. (2008) First-Bite Syndrome after Parapharyngeal Surgery for Cervical Schwannoma. The Journal of the American Dental Association, 139, 1480-1483. http://dx.doi.org/10.14219/jada.archive.2008.0073

[13] Kawashima, Y., Sumi, T., Sugimoto, T. and Kishimoto, S. (2008) First-Bite Syndrome: A Review of 29 Patients with Parapharyngeal Space Tumor. Auris Nasus Larynx, 35, 109-113. http://dx.doi.org/10.1016/j.anl.2007.06.005

[14] Chiu, A.G., Cohen, J.I., Burningham, A.R., Andersen, P.E. and Davidson, B.J. (2002) First Bite Syndrome: A Complication of Surgery Involving the Parapharyngeal Space. Head and Neck, 24, 996-999. http://dx.doi.org/10.1002/hed.10162

[15] Houle, A. and Mandel, L. (2014) First Bite Syndrome after Deep Lobe Parotidectomy: Case Report. Journal of Oral and Maxillofacial Surgery, 72, 1475-1479. http://dx.doi.org/10.1016/j.joms.2014.02.010

[16] Sims, J.R. and Suen, J.Y. (2013) First Bite Syndrome: Case Report of 3 Patients Treated with Botulinum Toxin and Review of Other Treatment Modalities. Head and Neck, 35, E288-E291. http://dx.doi.org/10.1002/hed.23150

[17] Lee, B.J., Lee, J.C., Lee, Y.O., Wang, S.G. and Kim, H.J. (2009) Novel Treatment of First Bite Syndrome Using Botulinum Toxin Type A. Head and Neck, 31, 989-993. http://dx.doi.org/10.1002/hed.21054

[18] Ali, M.J., Orloff, L.A., Lustig, L.R. and Eisele, D.W. (2008) Botulinum Toxin in the Treatment of First Bite Syndrome. Otolaryngology—Head and Neck Surgery, 139, 742-743. http://dx.doi.org/10.1016/j.otohns.2008.08.015

[19] Amin, N., Pelser, A. and Weighill, J. (2014) First Bite Syndrome: Our Experience of Laser Tympanic Plexus Ablation. The Journal of Laryngology \& Otology, 128, 166-168. http://dx.doi.org/10.1017/S002221511300354X

[20] Phillips, T.J. and Farquhar-Smith, W.P. (2009) Pharmacological Treatment of a Patient with First-Bite Syndrome. Anaesthesia, 64, 97-98. http://dx.doi.org/10.1111/j.1365-2044.2008.05804.x

[21] Prisco, L., Ganau, M., Bigotto, F. and Zornada, F. (2011) Trigeminal Neuralgia: Successful Antiepileptic Drug Combination Therapy in Three Refractory Cases. Drug, Healthcare and Patient Safety, 3, 43-45. http://dx.doi.org/10.2147/DHPS.S22385 